\title{
Muscle volume is a critical determinant of rowing performance in Olympic rowers
}

\author{
Author(s) \\ van der Zwaard, Stephan; Weide, Guido; Levels, Koen; Eikelboom, Michelle; Noordhof, \\ Dionne A.; Hofmijster, Mathijs J.; van der Laarse, Willem J.; de Ruiter, Cornelis J.; de Koning, \\ Jos J.; Jaspers, Richard T. \\ DOI \\ 10.1249/01.mss.0000519047.24644.bc
}

\section{Publication date}

2017

\section{Published in}

Supplement $15 S$

\section{License}

CC BY

Link to publication

\section{Citation for published version (APA):}

van der Zwaard, S., Weide, G., Levels, K., Eikelboom, M., Noordhof, D. A., Hofmijster, M. J., van der Laarse, W. J., de Ruiter, C. J., de Koning, J. J., \& Jaspers, R. T. (2017). Muscle volume is a critical determinant of rowing performance in Olympic rowers. In Supplement $15 S$ (5 ed., Vol. 49, pp. 768-769). (MEDICINE AND SCIENCE IN SPORTS AND EXERCISE). https://doi.org/10.1249/01.mss.0000519047.24644.bc

If you believe that digital publication of certain material infringes any of your rights or (privacy) interests,

please let the Library know, stating your reasons. In case of a legitimate complaint, the Library will make the material inaccessible and/or remove it from the website. Please contact the library:

https://www.amsterdamuas.com/library/contact/questions, or send a letter to: University Library (Library of the University of Amsterdam and Amsterdam University of Applied Sciences), Secretariat, Singel 425, 1012 WP Amsterdam, The Netherlands. You will be contacted as soon as possible.

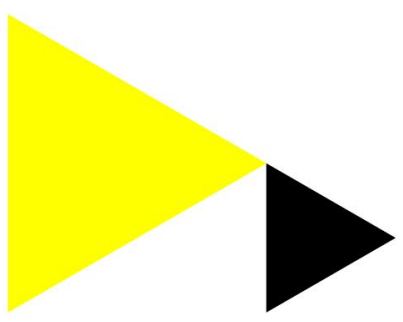




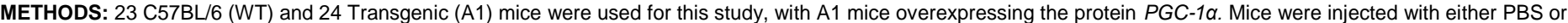
Bupivacaine (MAR) at 12 weeks of age. Tibialis anterior (TA) muscle and tibias were excised 3-days post injection. Tissue was immediately frozen for gene expression analysis using RT-qPCR.

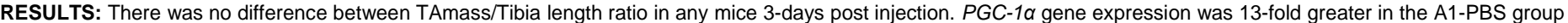

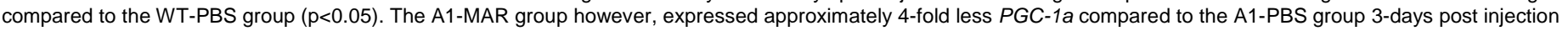

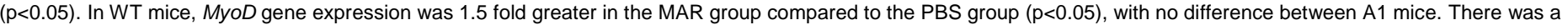

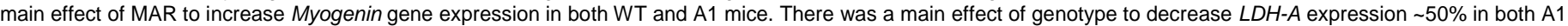

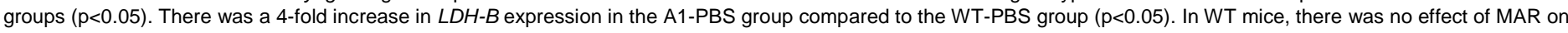

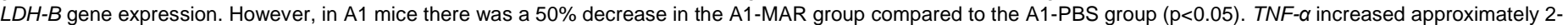
fold as a main effect of genotype in both $A 1$ groups $(p<0.05)$.

CONCLUSION: A surplus of mitochondria may result in more ROS production and higher levels of $T N F$ - $\alpha$, resulting in altered expression of $M y o D$. With $T N F-\alpha$ possibly

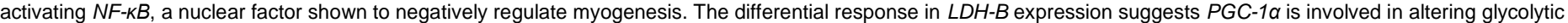
energy metabolism at the onset of muscle regeneration.

\section{Board \#208 June 2 11:00 AM - 12:30 PM}

Reliability and Comparison of Measurements of the Tibialis Posterior Cross-Sectional Area Via Ultrasound Imaging

Victoria A. Violette, Sarah T. Ridge, Dustin Bruening, J W. Myrer, A. W. Johnson. Brigham Young University, Provo, UT. (Sponsor: Pat Vehrs, FACSM)

(No relationships reported)

PURPOSE: The tibialis posterior is a key muscle in controlling the medial longitudinal arch. Being able to assess the strength, activity and size of the muscle is crucial in

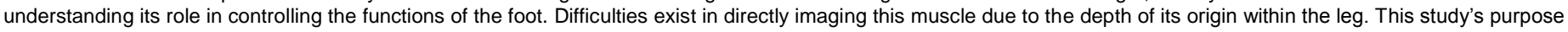
was to evaluate techniques used to image the TP muscle size using ultrasound.

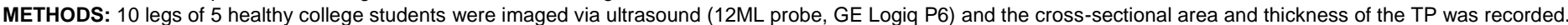

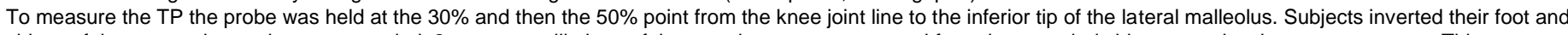

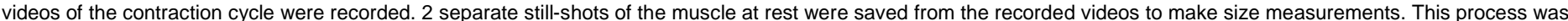
performed on both anterior and posterior sides of the leg. To assess reliability intraclass correlation coefficients (ICC) were calculated. A correlation was performed to compare anterior to posterior measurements.

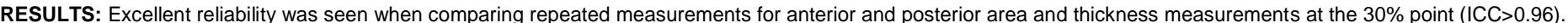

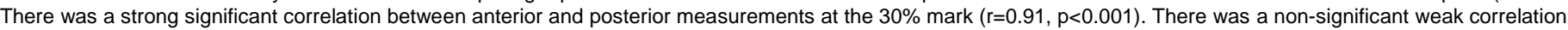

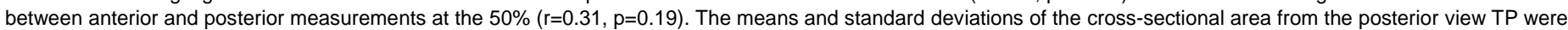
$4.35 \pm 0.49 \mathrm{~cm}^{2}(30 \%)$ and $3.78 \pm 0.47 \mathrm{~cm}^{2}(50 \%)$. While the anterior view cross-sectional areas' were $4.18 \pm 0.49 \mathrm{~cm}^{2}(30 \%)$ and $3.42 \pm 0.46 \mathrm{~cm}^{2}(50 \%)$.

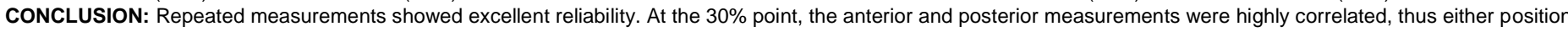
could be used to image the TP. The anterior view, at the $50 \%$ should generally not be used because portions of the TP were often hidden behind bone which decreased accuracy of the measurement.

2689
Board \#209
June 2 11:00 AM - 12:30 PM

Thigh Muscle Architecture Changes During a Soccer Season in Previously Injured and Non-injured Female Athletes

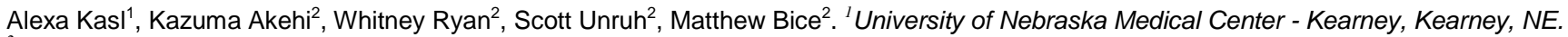
${ }^{2}$ University of Nebraska at Kearney, Kearney, NE.

Email: kasla2@lopers.unk.edu

(No relationships reported)

Very little research has investigated muscle morphological and architectural characteristic changes on the individual thigh muscles during a competitive season in previously injured and non-injured collegiate athletes. Such research may provide important insight into sport-induced anatomical changes, which could have a significant impact on muscle performance and injury risks.

PURPOSE: To examine the influence of competitive women's college soccer participation on thigh and hamstring muscles' morphological and architectural characteristics. METHODS: Eighteen soccer players (Previously injured $n=8$, age $=20.43 \pm 0.90 \mathrm{yrs}$; Non-injured $\mathrm{n}=10$ : age $=20.31 \pm 1.38$ yrs) volunteered to participate in the study. Participants reported a total of 4 times separated by 4 weeks during the season and underwent ultrasound testing to assess changes in muscle thickness (MT; $\mathrm{cm}$ ), subcutaneous tissue thickness $(\mathrm{ST} ; \mathrm{cm})$, pennation angle (PA; ${ }^{\circ}$ ), and echo intensity (EI) of the rectus femoris (RF), vastus medialis (VM), vastus medialis oblique (VMO), vastus lateralis (VL), vastus intermedius $(\mathrm{VI})$, and biceps femoris $(\mathrm{BF})$ muscles and thigh circumference measures using a tape measure. A 3-way (dominant side of the leg $\mathrm{x}$ injury history $\mathrm{x}$ time) ANOVA with repeated measure was used to analyze each variable. When interactions were present, Tukey-Kramer multiple comparison post-hoc tests were used.

RESULTS: MT of the RF, VI, VM, and VMO muscles increased between 4.4 and $14.5 \%$ at week 4 and 8 during the season $(P<.02)$ regardless of the dominant side of the leg or injury history. El of RF, VL, and VM muscles decreased between 3.1 and $8.1 \%$ at week 4 and 8 during the season $(P<.01)$.

CONCLUSION: These results indicated that, muscle size and quality had improved in non-injured athletes but had diminished in those who were previously injured. Because no time-related differences in thigh circumference measures were observed it is possible that these measures may not be sensitive enough for detecting morphological changes. Given the relationship between muscle size and quality, it is possible that these unique morphological and architectural adaptations over time may influence athletic performance and/or potential risks of musculoskeletal injuries; however, future studies are needed to test these hypotheses.

Supported by NRI Grant 15-060

2690 Board \#210 June 2 11:00 AM - 12:30 PM

Muscle Volume Is A Critical Determinant Of Rowing Performance In Olympic Rowers

Stephan van der Zwaard ${ }^{1}$, Guido Weide ${ }^{1}$, Koen Levels ${ }^{1}$, Michelle Eikelboom ${ }^{1}$, Dionne A. Noordhof ${ }^{1}$, Mathijs J. Hofmijster ${ }^{1}$, Willem J. van der Laarse $^{2}$, Cornelis J. de Ruiter ${ }^{1}$, Jos J. de Koning, FACSM ${ }^{1}$, Richard T. Jaspers ${ }^{1} .{ }^{1}$ Vrije Universiteit, Amsterdam, Netherlands. ${ }^{2}$ VU University Medical Center, Amsterdam, Netherlands. (Sponsor: Jos de Koning, FACSM) Email: s.vander.zwaard@vu.nl

(No relationships reported)

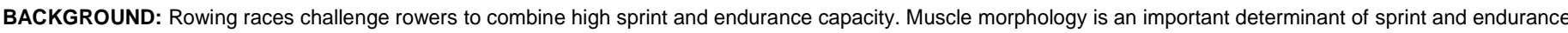
capacities and as such may also be a critical determinant of rowing performance.

PURPOSE: To determine how much of the rowing performance of Olympic rowers is explained by sprint and endurance capacity and by muscle morphology.

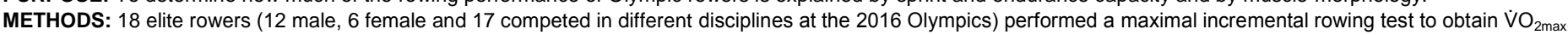

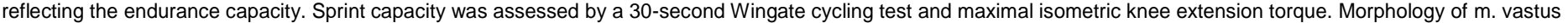




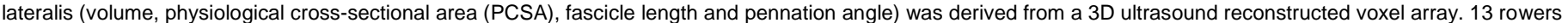

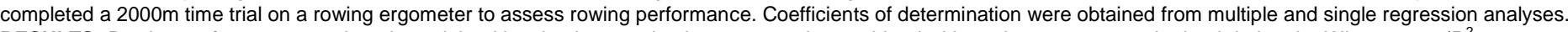

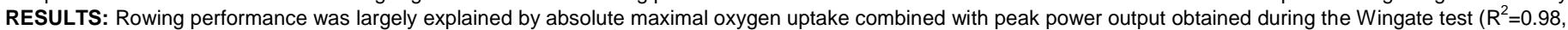
$\mathrm{p}<0.001)$. Muscle volume largely explained rowing performance $\left(r^{2}=0.85, p<0.001\right)$ and was strongly related to Wingate peak power output $\left(r^{2}=0.82, p<0.001\right), \dot{V} O_{2 m a x}$

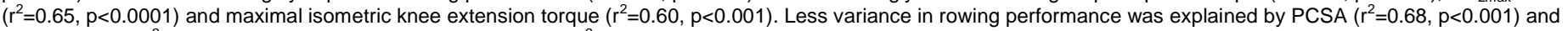
fascicle length $\left(r^{2}=0.43, p<0.05\right)$ and none by pennation angle $\left(r^{2}=0.00, p=0.774\right)$.

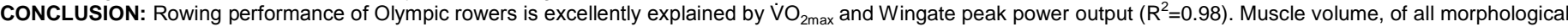
properties, is the most important determinant of rowing ergometer performance, and endurance and sprint capacity in Olympic rowers.

Funding: Technologiestichting STW

2691 Board \#211 June 2 11:00 AM - 12:30 PM

Effects Of Time-of-day Specific Resistance Training On Muscle Strength And Muscular Il-6-associated Signaling In Male Rats

Szu-Hsien Yu ${ }^{1}$, Shueh-I Lin ${ }^{1}$, Shih-Chang Cheng ${ }^{1}$, Chung-Pu Chi ${ }^{2}$, Chia-Hua Kuo, FACSM ${ }^{3}$. ${ }^{1}$ National ILan University, Yilan City, Taiwan.

${ }^{2}$ Taipei Medical University, Taipei, Taiwan. ${ }^{3}$ University of Taipei, Taipei, Taiwan. (Sponsor: Chia-Hua Kuo, FACSM)

Email: meek168@hotmail.com

(No relationships reported)

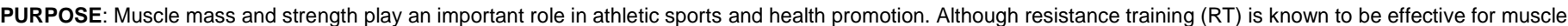

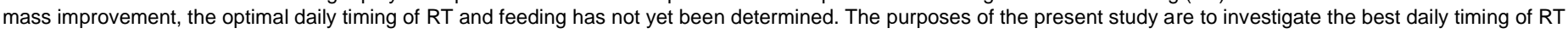
for the muscle hypertrophy in male rats.

METHODS: In study I, SD rats were divided into Control (C, non-exercise), Early (E, beginning of active phase, 8:00) and Late (L, end of active phase, 17:00). Rats of exercise groups ( $E$ and $L$ ) were asked to perform RT by climbing for 10 weeks in beginning and end of active phase respectively. Climbing strength and weight of flexor

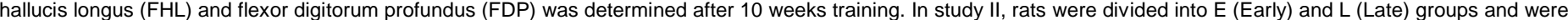
performed an acute RT by climbing. FDP muscle samples were obtained 2, 6 and 24 hours after RT.

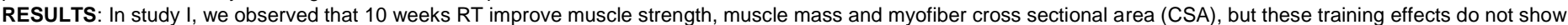

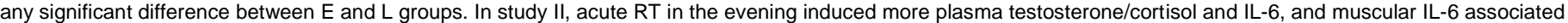
signaling such as phosphorylation of STAT1 and STAT3 compared to training in the morning.

CONCLUSIONS: we suggest that resistance exercise-induced IL-6 signal in skeletal muscle is not the main source of 10 weeks resistace training adaptation.

2692 Board \#212 June 2 11:00 AM - 12:30 PM

Characterization of Protein Metabolism in Undifferentiated and Differentiated Murine Muscle Tissue

Jessica M. Cardin, J. William Deaver, Colleen L. O’Reilly, Stephen F. Crouse, FACSM, James D. Fluckey. Texas A\&M University, College Station, TX. (Sponsor: Stephen F. Crouse, FACSM)

(No relationships reported)

The emergence of cell culture experiments have greatly expanded the understanding of skeletal muscle physiology. However, there is a paucity of data regarding the behaviors of cells grown in culture at various stages versus in vivo. This preliminary set of studies was designed to assess alterations of anabolic responses between undifferentiated and differentiated muscle tissue.

PURPOSE: Determine if there is a disparity in fractional synthesis rates (FSR) between C2C12 myoblasts and myotubes. ${ }^{*} 100$

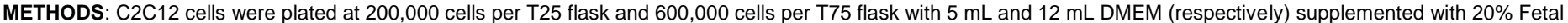

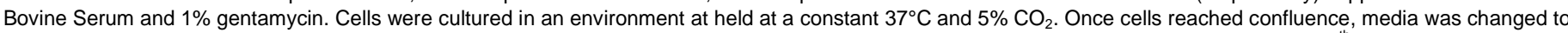

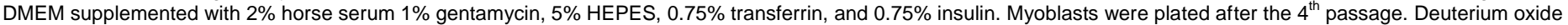

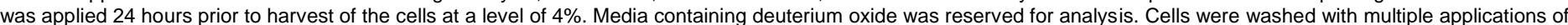

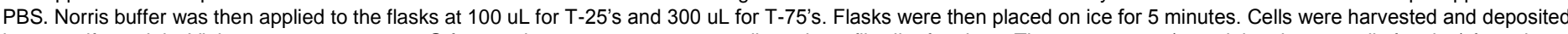

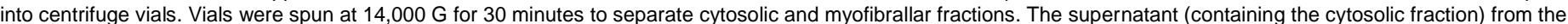
vial was decanted into another vial and saved for analysis. $2 \mathrm{H}$-alanine and plasma enrichment was determined by GC-MS and FSR was calculated by:

RESULTS: Preliminary data demonstrates that differentiated murine myotubes have $\sim 76 \%$ FSR of the undifferentiated murine myoblasts ( $<<0.005)$.

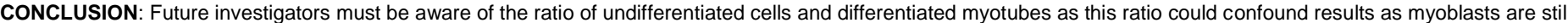
present even at later stages of differentiation.

Board \#213 June 2 11:00 AM - 12:30 PM

Partial or Complete Unloading of Skeletal Muscle Leads to Specific Alterations of Anabolic Signal Transduction Colleen L. OReilly ${ }^{1}$, J William Deaver ${ }^{1}$, Michael P. Wiggs ${ }^{2}$, Florence Lima ${ }^{1}$, Joshua M. Swift ${ }^{3}$, Elizabeth S. Greene ${ }^{4}$, Susan A. Bloomfield, FACSM ${ }^{1}$, James D. Fluckey ${ }^{1} .{ }^{I}$ Texas A\&M University, College Station, TX. ${ }^{2}$ UT-Tyler, Tyler, TX. ${ }^{3}$ USUSH, Bethesda, MD. ${ }^{4}$ University of Arkansas, Fayetteville, TX. (Sponsor: Susan A Bloomfield, FACSM)

(No relationships reported)

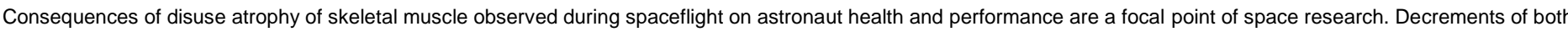

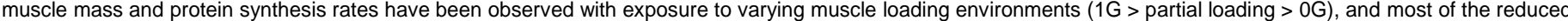

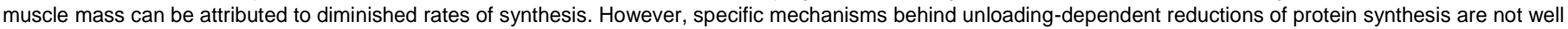
defined.

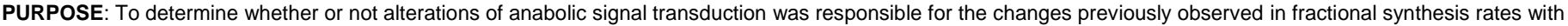
specific gravitational loading paradigms.

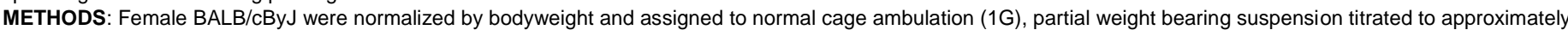

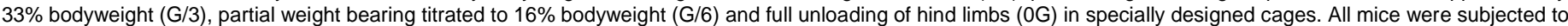

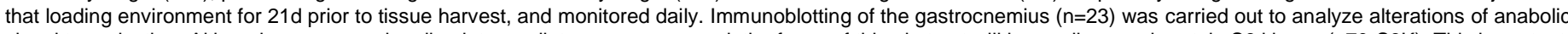

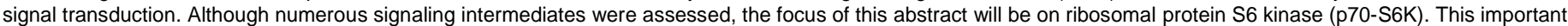
protein has served as a marker of protein synthesis signal transduction as well as the anabolic capacity in skeletal muscle.

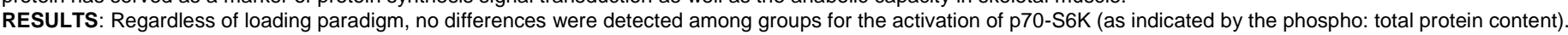
Total protein content, however, was 27\% lower than control in $0 G$ and $G / 6(P=0.008)$ with $G / 3$ not being different from control ( $P>0.05)$.

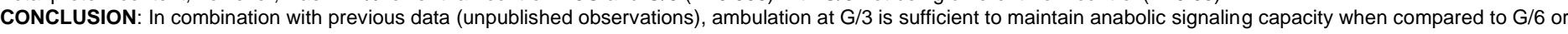
$0 G$, suggesting that a threshold level of stimulus is necessary to maintain anabolic capacity in muscle. These results may have important implications towards the development of strategies designed to counter the effects of partial/complete unloading on skeletal muscle based on how the anabolic capacity of muscle is affected. 